\title{
Interpersonal comparison, status and ambition in organizations
}

\author{
Florian Ederer ${ }^{\mathrm{a}}$, Andrea Patacconi ${ }^{\mathrm{b}, *}$ \\ a Anderson School of Management, University of California at Los Angeles, 110 Westwood Plaza, Cornell Hall, D515, Los Angeles, CA 90095-1481, USA \\ ${ }^{\mathrm{b}}$ University of Aberdeen Business School, Edward Wright Building, Dunbar Street, Old Aberdeen AB24 3QY, United Kingdom
}

\section{A R T I C L E I N F O}

\section{Article history:}

Received 7 February 2007

Received in revised form 21 March 2010

Accepted 22 March 2010

Available online 31 March 2010

\section{JEL classification:}

$\mathrm{J} 31$

$\mathrm{J} 41$

\section{Keywords:}

Reference-dependent preferences

Status

Ambition

Tournaments

\begin{abstract}
A B S T R A C T
This paper shows that introducing status concerns into a tournament model has substantial implications for the provision of incentives. We emphasize the role of reference groups and determine the optimal number of winners and losers in tournaments. To compensate employees for the disutility of low status, a profit-maximizing employer may be reluctant to demote employees and instead reward workers through promotions. This rationalizes the prevalence of compensation systems which reward winners without explicitly identifying losers. Differences in ambition and ability affect contestants' efforts and may result in inefficient promotion outcomes. We analyze how to mitigate these inefficiencies when managing a diverse workforce by using mixed and segregated tournaments.
\end{abstract}

(c) 2010 Elsevier B.V. All rights reserved.

\section{Introduction}

In a seminal paper Baker et al. (1988) discuss a number of common features of organizational compensation systems that are hard to reconcile with the standard theory of incentives. Among these they include the prevalence of compensation systems that reward 'winners' without explicitly identifying 'losers'. This paper provides a rationale for the asymmetric effects of rewards and punishments and for other puzzling features of actual compensation systems.

We consider a simple tournament model in which $N$ risk-neutral agents compete for a set of prizes. However, we make the realistic assumption that workers care about their relative standing, that is, their status within a group. In our model, individual concerns for relative standing are captured by the reference-dependent nature of workers' preferences. ${ }^{1}$ Thus, a worker's utility depends not only on his wage $w$ and effort $e$, as in standard incentives models, but also on a "reference" or "typical" wage, $w^{R}$. Nonpecuniary gains and losses relative to $w^{R}$ are interpreted as measuring the magnitude of the worker's status concerns relative to a chosen reference group. In particular, we posit that people dislike being behind in terms of status in the organization, but enjoy being ahead of individuals in their reference group.

A crucial feature of this type of models is exactly how the reference point is determined. While in reality both objective and subjective considerations are likely to affect the choice of $w^{R}$, in the first part of the paper we focus on objective factors and assume that the reference wage is the wage that most workers participating in the tournament will receive. For instance, if few workers are promoted or demoted and most remain at the same intermediate level, then the 'typical' wage is the one

\footnotetext{
* Corresponding author. Tel.: +44 1224273423.

E-mail addresses: ederer@ucla.edu (F. Ederer), a.patacconi@abdn.ac.uk (A. Patacconi).

1 See among others Kahneman and Tversky (1979) and Koszegi and Rabin (2004).
} 
paid at the intermediate level. Likewise, if the majority of workers receive a bonus of 3 percent of their current salary, then a bonus of 3 percent is the typical salary premium.

In this setting we study how a firm can take advantage of the interpersonal comparison of its workforce to increase profits. The most important finding is that, if the workers' participation constraints are binding, the firm must compensate its employees for the disutility that they may derive from low status. Therefore the firm may be particularly reluctant to penalize or demote employees. In particular, and in contrast to a standard setting without status concerns (e.g., Lazear and Rosen, 1981), we show that the choice of the tournament format is not neutral, and the firm is better off choosing tournaments that reward winners instead of tournaments that penalize losers, since the former make positive outcomes salient. When both promotion and demotions are considered, we show that under mild conditions it is optimal for the firm to minimize the number of demotions and maximize the number of promotions, subject to a reference-wage constraint that identifies which of the prizes in the tournament is the reference wage. The model also sheds light on other features of actual incentive schemes such as small salary premia, rat races and job title proliferation.

In the second part of the paper we turn attention to the personal, idiosyncratic factors that determine reference points. In particular, we allow for individual differences in ambition, where ambition is defined as the tendency to set for oneself a high reference point. This definition is consistent with the central argument put forward by Heath et al. (1999) who argue that goals can serve as reference points. Differences in ambition are interpreted and related to differences in reference groups: for instance, women may have lower reference wages because they compare themselves not with workers in general (male and female) but only with other female workers. Analogously, high ability workers may have higher reference wages because they compare themselves only with other talented individuals. ${ }^{2}$ We show that ambitious workers always exert more effort in equilibrium than their unambitious colleagues and that both types exert more effort in a segregated tournament than in a mixed setting. We discuss our findings in light of the experimental findings documenting differential performances in mixed and segregated tournament settings between men and women. If, as suggested by previous contributions, men set for themselves higher reference points than women, then it is possible to explain these experimental findings and the observed gender wage and promotion rate gap without invoking discrimination or differences in ability or in outside opportunities. We further allow workers to differ also in terms of ability. In such a setting, it is well-known that tournaments cannot in general match employees to the jobs for which they are best suited, since performance in the current job is not necessarily the best indicator of performance in another job (Baker et al., 1988). We question the practical relevance of that claim in the light of the fact that empirically ambition and ability are positively correlated. Our model shows that if more able workers compare themselves to equally able workers and not to lower ability workers, then more able individuals will exert more effort, thereby further increasing their chances of winning the tournament and reducing the probability of an inefficient promotion decision. Finally, we investigate the human resource question of whether an organization should run mixed or segregated tournaments. We show that if differences in ambition are large relative to differences in ability, then even firms that only care about promoting their most talented employees may find it optimal to design segregated tournaments since this effectively implements a quota system for their less ambitious employees. In contrast, firms that mostly care about performance in the current job always implement segregated tournaments. This is because segregated tournaments create balanced competitions which in turn induce contestants to exert more effort.

The key behavioural assumption of this paper is that people intrinsically care about relative standing. Frank (1985), Robson (1992) and Zizzo (2002) also note that status might be valued per se. Huberman et al. (2004) provide experimental evidence that subjects value status independently of any monetary consequences and are willing to trade off some material gain in order to obtain it. Heath et al. (1999) argue that goals serve as reference points and alter outcomes in a manner consistent with the value function of Prospect Theory (Kahneman and Tversky, 1979). They present evidence that goals inherit key properties of the value function such as a reference point and loss aversion. Furthermore, there seems to be a reasonable amount of heterogeneity with respect to status-seeking behavior, in particular, marked gender and country differences (Falk and Knell, 2004; Huberman et al., 2004; Gneezy et al., 2003).

Despite the vast body of empirical and experimental evidence on status and reference-dependency, until recently little attention has been paid to the development of models of the labour market that incorporate these preferences. The large majority of papers that incorporate these preferences do so by modeling the status of an agent as an increasing function of the wage difference between the agent and other workers or the principal. ${ }^{3}$ That is, the more an agent earns relative to his comparison group, the higher is his status. Fershtman et al. (2006), for instance, examine the effects of differences in importance that workers give to their status relative to other workers to whom they compare themselves. They show that, for equally productive workers, wages may vary, reflecting the different incentives that firms provide to workers with different social concerns. Fershtman et al. (2003); Goel and Thakor (2006) show that when workers (or managers) care about relative status, the optimal provision of incentives involves some form of joint performance evaluation, where the wage of

\footnotetext{
2 To maintain analytical tractability, however, in the second part of the paper we consider only two-agent tournaments and set aside the role that external factors have in determining the reference point.

3 A notable exception is the paper by Auriol and Renault (2008) in which status is not tied to wages since firms can provide status symbols that are independent of wages and are costless for the firm.
} 
one agent is positively related to the performance and the wage of the other agents in the reference group even though outputs are uncorrelated.

More closely related to the present paper is the work of Demougin and Fluet (2003) and Grund and Sliwka (2005) who also focus on tournaments. While we concentrate on status concerns, they analyze the effects of inequity aversion, broadly defined as a preference for equitable or fair outcomes (e.g., Fehr and Schmidt, 1999; Bolton and Ockenfels, 2000). As in their papers we find a positive incentive effect of behindness-aversion ('envy'). However, these papers only focus on the symmetric two-player case. Therefore, they cannot study the determination of the optimal number of winners and losers and do not provide an explanation for the prevalence of promotion-based tournaments in practice. Furthermore, since they do not allow for heterogeneity among agents, they are unable to explore the interaction effects of ambition and ability as well as the resulting asymmetries in effort choices. ${ }^{4}$

The remainder of the paper proceeds as follows. In Section 2 we introduce the model and discuss two-prize tournaments. Section 3 extends the basic model to examine both promotions and demotions. Section 4 introduces worker heterogeneity in terms of ambition, while Section 5 allows for ability differences. Section 6 concludes. All the omitted proofs are gathered in Appendix A.

\section{The basic model}

There are $N$ identical workers, or agents, indexed $i=1,2, \ldots, N, N \geq 2$, who compete in a tournament. We begin by considering a simple set-up where the $N_{W} \geq 1$ agents who produce the most output receive a wage $w_{H}$, while the remaining workers $N_{L} \equiv N-N_{W}$ receive a wage $w_{L}$. Individual output is given by $x_{i}=e_{i}+\varepsilon_{i}$, where $e_{i}$ denotes worker $i$ 's effort and $\varepsilon_{i}$ is an error term with cumulative density function $F(\cdot)$, density $f(\cdot)$ and zero mean. We write $i \in W$ if agent $i$ is one of the $N_{W}$ workers that produce the most output; otherwise we write $i \in L .{ }^{5}$ Let $w^{R} \in\left[w_{L}, w_{H}\right]$ denote a reference wage. This wage represents the 'normal' or 'typical' wage that the agents expect to obtain by participating in the tournament. Agent $i$ 's expected utility for any choice of effort is given by

$$
E u_{i}\left(e_{i}\right)=\operatorname{Pr}(i \in W)\left[w_{H}+\beta\left(w_{H}-w^{R}\right)\right]+\operatorname{Pr}(i \in L)\left[w_{L}+\alpha\left(w_{L}-w^{R}\right)\right]-c\left(e_{i}\right)
$$

where the function $c(\cdot)$ denotes the cost of effort and is assumed to be strictly increasing and convex. Eq. (1) captures the idea that in addition to monetary incentives, agents are also motivated by their relative standing within the group. That is, they enjoy earning a wage that they consider high with respect to some standard, and dislike being below that threshold. The parameters $\alpha$ and $\beta$, where $\alpha, \beta \geq 0$, measure the importance of interpersonal comparisons and, more specifically, how much workers dislike being 'losers' and enjoy being 'winners', respectively. We say that workers care more about relative status if $\alpha$ and $\beta$ are higher. We also assume that $\alpha \geq \beta$ since there is very strong evidence that losses generally resonate more strongly than gains (see, e.g., Kahneman and Tversky, 1992).

Our framework is similar to the one commonly adopted in the inequity-aversion literature which uses the same specification, but assumes that $\beta \leq 0$, e.g. Fehr and Schmidt (1999). Although in some settings agents may dislike receiving more than their peers, it is our belief that in competitive scenarios like promotion tournaments the assumption that $\beta \geq 0$ is an equally good, if not better, description of actual behavior. Even Fehr and Schmidt (1999) "believe that there are subjects with $\beta \geq 0$ ", and that in competitive settings these particular inequity considerations are less important (Fehr and Schmidt, 2003). Furthermore, there is ample empirical evidence that status considerations where individuals benefit from receiving higher wages than their peers play an important role in the workplace (Frank, 1985). For example, using ordered probit models Clark and Oswald (1996) show that workers' satisfaction levels are negatively related to their comparison earnings levels as defined by their expected or predicted wage, both when workers earn less and when they earn more than their comparison earning level. Moreover, Clark et al. (2008, p. 137) argue that "the broad consensus in the literature is that the [Easterlin] paradox points to the importance of relative considerations in the utility function, where higher income brings both consumption and status benefits to an individual" and that "comparisons can either be to others or to oneself in the past". ${ }^{6}$ Note also that we assume that effort choices do not enter in agents' relative payoff comparisons. This means that status only depends on a comparison of wages, rather than action-adjusted wages. The rationale for this assumption is that it is more difficult to observe effort costs than rewards. Throughout it is assumed that agents make their effort choices privately and so they can only observe and compare their ex-post realized wages. ${ }^{7}$

\footnotetext{
4 Our work is also related to a number of papers in the behindness aversion ('envy') literature, including Bartling and von Siemens (in press) and Dur and Glaser (2008), and in the inequity aversion literature, including Rey Biel (2008), Englmaier and Wambach (2005), and Itoh (2004). Our paper differs from these contributions in that we analyze a tournament setting with multiple agents.

5 The assumption that workers compete for promotion slots means that relative performance determines the identity of 'winners' and 'losers'. This is in contrast to models where the performance of one's co-workers does not affect one's probability of promotion, since promotions are determined only by the worker's absolute level of performance. DeVaro (2006) provides evidence that relative performance of workers determines promotions.

${ }^{6}$ Our specification also encompasses the modeling approaches adopted by a series of other theoretical papers. If $\beta=0$ then the agent only suffers from envy as in Dur and Glaser (2008) and Bartling and von Siemens (in press). If $\beta=\alpha$ then our specification is identical to that of Fershtman et al. (2003, 2006) and similar to Goel and Thakor (2006).

7 The alternative specification in which agents compare action-adjusted wages would imply that agents would not be as averse to the high wage realizations of other agents if they believed that these other agents worked harder. However, even with this alternative specification our analysis remains
} 
A key element of the analysis is to identify plausible values for the reference wage $w^{R}$. This is perhaps the thorniest issue in the theory of reference-dependent preferences, and several possibilities have been explored. Here we assume that the 'typical' wage $w^{R}$ is that received by the modal group of workers. To be 'typical', however, we also require the modal group to be considerably larger than the other group(s). We formalize this idea by assuming that the number of people belonging to the modal group exceeds the number of individuals in the other group by $D \geq 1$. However, if no such group exists, we take the reference wage to be equal to the average of all the wages received by the agents, i.e. $w^{R}=(1 / N) \sum_{i=1}^{N} w_{i}$. Formally we assume that $w^{R}=w_{H}$ if $N_{W} \geq N_{L}+D, w^{R}=w_{L}$ if $N_{L} \geq N_{W}+D$, and $w^{R}=1 / N \sum_{i}^{N} w_{i}$ otherwise.

This definition implies that in a tournament where there is only one winner and many losers, the reference wage equals $w_{L}$. Thus workers not promoted in tournaments where there is only a small number of winners, will not perceive themselves as 'losers' but as being 'normal'. In this section and the next we will also assume that $D \leq N-2$, so that in principle a reference group can always be created. This is important because we will show that a profit-maximizing firm always has an incentive to set a reference group so that it can reward winners without explicitly identifying losers.

Our goal is to study the behavior of a firm (principal) which takes into account the interpersonal comparison component of workers' preferences. The firm's profits are the sum of the agents' outputs multiplied by the marginal value product $V$ which is the price of one unit of output $x$. Its objective is to maximize expected profits

$$
\max _{w_{H}, w_{L}, N_{H}, N_{L}} E \Pi=V \sum_{i=1}^{N} e_{i}-N_{W} w_{H}-N_{L} w_{L}
$$

with respect to the endogenous variables $w_{H}, w_{L}, N_{H}$ and $N_{L}$, subject to the workers' incentive and participation constraints ${ }^{8}$ :

$$
e_{i} \in \arg \max E u_{i}\left(e_{i}\right) \text { and } E u_{i}\left(e_{i}\right) \geq \bar{u} \text { for all } i .
$$

This problem can be considerably simplified by focusing on a symmetric equilibrium where all workers exert the same effort $e$. In that case, each worker has the same chance of winning the tournament and therefore $\operatorname{Pr}(i \in W)=N_{W} / N$ and $\operatorname{Pr}(i \in L)=\left(N-N_{W}\right) / N$. Since the participation constraints must bind at the optimum, $E u_{i}\left(e_{i}\right)=\bar{u}$ for all $i$. Plugging the binding participation constraint into the expected profits yields

$$
E \Pi=V N e-N[\bar{u}+c(e)]+N_{W} \beta\left(w_{H}-w^{R}\right)+\left(N-N_{W}\right) \alpha\left(w_{L}-w^{R}\right) .
$$

We can also replace the workers' incentive constraints with the corresponding first-order conditions ${ }^{9}$ :

$$
\frac{\partial \operatorname{Pr}(i \in W)}{\partial e_{i}}\left[\left(w_{H}-w_{L}\right)+\alpha\left(w^{R}-w_{L}\right)+\beta\left(w_{H}-w^{R}\right)\right]=c^{\prime}\left(e_{i}\right) .
$$

The firm's objective can thus be rewritten as to maximize (2) with respect to $w_{H}, w_{L}, N_{W}$ and $N_{L}$ subject to (3).

\subsection{Tournament scenarios}

To provide a foundation and some intuition for the following results, the remainder of this section will compare three specific tournament scenarios in terms of equilibrium effort and profits. For now we will take the number of winners and losers in each tournament scenario as exogenously given. The next section will then study the optimal choice of $N_{W}$ and $N_{L}$ in a more general framework and show how the reference wage should be optimally set.

\subsubsection{Benchmark without status concerns $(\alpha=\beta=0)$}

We begin with the standard set-up where a firm's workforce is only motivated by absolute monetary rewards. For given $N_{W}$ and $N_{L}$, the problem of the firm when $\alpha=\beta=0$ reduces to ${ }^{10}$

$$
\max _{e} E \Pi^{T}=V N e-N[\bar{u}+c(e)]
$$

subject to

$$
\frac{\partial \operatorname{Pr}(i \in W)}{\partial e_{i}}\left(w_{H}-w_{L}\right)=c^{\prime}\left(e_{i}\right)
$$

unchanged as long as all agents are ex-ante identical and a symmetric equilibrium in effort choices exists. In that case, in fact, agents would exert the same effort and relative status would only be affected by the ex-post realization of wages. Note, however, that a symmetric equilibrium may not exist when agents strongly care about receiving their "just deserts", i.e. what they feel they deserve (Gill and Stone, 2009).

8 We do not impose limited liability which would require $w_{H}, w_{L} \geq 0$. Thus, the wages $w_{H}$ and $w_{L}$ could be negative as long as the participation constraint is satisfied. Furthermore, since the noise term is independent of the effort choice and thus cannot be influenced by the agent, for the risk-neutral principal maximizing effort and output is identical.

9 Throughout the paper we assume that $\partial \operatorname{Pr}(i \in W) / \partial e_{i}$ is strictly positive and finite. This implies that there must be at least one winner (i.e., $N_{W} \geq 1$ ).

10 Note that in (4a) we use workers' effort $e$ as the choice variable. This is legitimate because we can use the wage spread so as to induce any given effort level in equilibrium (see Eq. (4b)). Of course, $w_{L}$ and $w_{H}$ must also be set so that in equilibrium the participation constraint binds. 
This set-up is a multiagent generalization of standard textbook treatments of tournament theory. In the following we will compare this benchmark to the case where workers have concerns for relative standing, always assuming that the secondorder conditions of our programs are satisfied.

\subsubsection{Promotion-based tournaments}

In promotion-based tournaments, few workers receive the high wage ("are promoted") and the majority stay at the same level and receive the low wage. Thus, we assume $w^{R}=w_{L}$. We denote by $N_{W}^{P B}$ the number of promotion slots, where $N_{W}^{P B} \leq N_{L}^{P B}-D$. Eqs. (2) and (3) become

$$
\max _{e} E \Pi^{P B}=V N e-N[\bar{u}+c(e)]+N_{W}^{P B} \beta\left(w_{H}-w_{L}\right)
$$

subject to

$$
\frac{\partial \operatorname{Pr}(i \in W)}{\partial e_{i}}(1+\beta)\left(w_{H}-w_{L}\right)=c^{\prime}\left(e_{i}\right)
$$

Eq. (5a) differs from the benchmark case (4a) because of the term $N_{W}^{P B} \beta\left(w_{H}-w_{L}\right)$. In a promotion-based tournament it is in fact the identity of the winners that is salient, and that positively affects workers' utility. These gains, however, accrue to the firm because in equilibrium wages are set such that the participation constraint binds.

\subsubsection{Demotion-based tournaments}

In this type of tournaments, most workers receive the high prize while only a few receive the low prize. We interpret this situation as one where the majority of workers remain at the same hierarchical level (this time denoted by $H$ ) while the worst are demoted and receive the lower wage $w_{L}$. Thus, as in the previous scenario the typical outcome for a worker is to remain in his or her current job. The difference is that incentives are now provided by the threat of demotion, not the prospect of promotion. ${ }^{11}$

Since, by assumption, only a small number of workers receive the low wage, the reference wage is now $w_{H}$. Let $N_{W}^{D B}(\geq$ $N_{L}^{D B}+D$ ) denote the number of workers that stay at the same level. The problem of the firm is to

$$
\max _{e} E \Pi^{D B}=V N e-N[\bar{u}+c(e)]-\left(N-N_{W}^{D B}\right) \alpha\left(w_{H}-w_{L}\right)
$$

subject to

$$
\frac{\partial \operatorname{Pr}(i \in W)}{\partial e_{i}}(1+\alpha)\left(w_{H}-w_{L}\right)=c^{\prime}\left(e_{i}\right)
$$

The negative term $\left(N-N_{W}^{D B}\right) \alpha\left(w_{H}-w_{L}\right)$, which is absent both in the benchmark case and in promotion-based tournaments, now appears in (6a). These costs accrue because demotion-based tournaments, by making the identity of the $N-N_{W}^{D B}$ losers salient, tend to reduce workers' utility. This implies that in equilibrium a firm's profits must decrease, since the firm must guarantee its workers their reservation utility $\bar{u}$.

\subsection{Comparison of simple tournament scenarios}

We are now in a position to compare these tournament scenarios in terms of equilibrium effort choices and profits for any given $\left(N_{W}^{P B}, N_{W}^{D B}\right)$. We begin with the case where the wage spread $\Delta w=w_{H}-w_{L}$ is exogenously given.

Proposition 1. For any given wage spread, (i) equilibrium effort is higher when workers care about relative status than when they are only motivated by absolute monetary rewards. Furthermore, (ii) effort is higher in a demotion-based tournament than in a promotion-based tournament if workers are sufficiently loss averse (that is, $\alpha-\beta$ is sufficiently large).

Proof. First note that the marginal probability of winning is in general a function of $N_{W}$. To emphasize this fact, we write $\left(\partial \operatorname{Pr}\left(i \in W \mid N_{W}\right)\right) / \partial e_{i}$ instead of $(\partial \operatorname{Pr}(i \in W)) / \partial e_{i}$. Lemma A.1 in Appendix A shows that $\left(\partial \operatorname{Pr}\left(i \in W \mid N_{W}\right)\right) / \partial e_{i}$ is independent of $e$ since all workers choose the same level of effort. The first part of the proposition follows immediately from ( 3 ) and (4b). Part (ii) follows from the fact that $\left(\partial \operatorname{Pr}\left(i \in W \mid N_{W}^{D B}\right) / \partial e_{i}\right)(1+\alpha)\left(w_{H}-w_{L}\right)>\left(\partial \operatorname{Pr}\left(i \in W \mid N_{W}^{P B}\right) / \partial e_{i}\right)(1+\beta)\left(w_{H}-w_{L}\right)$ if $\alpha-\beta$ is sufficiently large.

Thus, as noted by Grund and Sliwka (2005) and Demougin and Fluet (2003), concerns for relative ranking induce contestants to exert more effort than standard tournament theory would predict - a result consistent with the experimental findings by Harbring and Irlenbusch (2008) and the view that interpersonal comparisons may lead toward wage compression in firms (Frank, 1984, 1985).

\footnotetext{
11 Promotion and demotion-based tournaments will be special cases of the general framework developed in Section 3, where workers can either be promoted, demoted, or remain at the same hierarchical level.
} 
Most importantly, our model predicts that effort should typically be higher in tournaments where losers are punished than in tournaments where winners are rewarded. Harbring and Irlenbusch (2003) provide empirical support for this prediction. They find that in a controlled economic laboratory setting average effort significantly increases with the proportion of winner prizes. Harbring and Irlenbusch (2008) report results on effort choices in tournaments in which the proportion of winner prizes varies across treatments with four and eight participants. While standard theory, based on the assumption of purely selfish agents, predicts that the provision of effort should be the same across the treatments, in line with the predictions of our model they show that on average productive effort is higher when the proportion of winners is large (75 percent) than when it is small (25 percent). ${ }^{12}$ Moreover, consistent with our theory, they find that the number of participants who completely drop out of the competition monotonically decreases with the number of winner prizes.

Our next step is to investigate how firm's profits vary with the choice of tournament format. If workers do not care about interpersonal comparisons, it is irrelevant to the firm whether tournaments are promotion-based or demotion-based. This is a standard result in the tournament literature which follows from Eqs. (4a) and (4b). The introduction of interpersonal comparison changes this result.

Proposition 2 (Asymmetric effects of rewards and punishments). Expected profits are higher in a promotion-based tournament than in a demotion-based tournament, both in the case where effort is fixed across scenarios and in the case when it is chosen optimally.

Proof. We begin with the case where effort $e$ is fixed at the same level across tournament scenarios. Eqs. (4a), (5a) and (6a) imply that for all $e, E \Pi^{P B}(e)>E \Pi^{T}(e)>E \Pi^{D B}(e)$. We can also show that the same relationship holds when effort levels are chosen optimally. To see this, let $e^{T}$ and $e^{P B}$ denote, respectively, the effort levels that solve (4a) and (5a). Then $E \Pi^{P B}\left(e^{P B}\right) \geq E \Pi^{P B}\left(e^{T}\right)>E \Pi^{T}\left(e^{T}\right)$, where the first inequality follows from the definition of optimality and the second from the relationship between $E \Pi^{P B}(e)$ and $E \Pi^{T}(e)$. A similar argument applies to demotion-based tournaments. Thus $E \Pi^{P B}\left(e^{P B}\right)>E \Pi^{T}\left(e^{T}\right)>E \Pi^{D B}\left(e^{D B}\right)$.

Proposition 2 offers a possible explanation for 'the prevalence of compensation systems that reward 'winners' without explicitly identifying 'losers"' (Baker et al., 1988, p. 607). In our model, compensation schemes such as demotion-based tournaments make the identity of the losers salient. This generates status costs $\alpha\left(N-N_{W}^{D B}\right) \Delta w$ that the firm must eventually bear since the participation constraint is binding. By contrast, promotion-based tournaments make the identity of the winners salient. Ego rents $\beta N_{W}^{P B} \Delta w$ are created, making it easier for the firm to meet the participation constraint. As a result promotion-based tournaments dominate demotion-based tournaments from the principal's perspective.

It is important to note that the status costs $\alpha\left(N-N_{W}^{D B}\right) \Delta w$ and the ego rents $\beta N_{W}^{P B} \Delta w$ depend not only on the intensity of status concerns $(\alpha, \beta)$, but also on the equilibrium level of effort through $\Delta w$. This suggests that the firm may wish to induce different effort levels in equilibrium to magnify or mitigate the impact of status on profits. This intuition is captured in the next result.

Proposition 3. When the wage spread is optimally chosen, effort is highest in a promotion-based tournament, lower in a traditional tournament and lowest in a demotion-based tournament.

According to Proposition 3, firms should optimally induce high levels of effort in a promotion-based tournament to magnify workers' ego rents. We refer to this situation as a rat race for relative status. In a demotion-based tournament, instead, the firms should induce low effort levels (relative to the orthodox case without status concerns) to mitigate the impact of status on profits. As status concerns become more important, the differences between these effort levels will become more pronounced.

We conclude this section by examining the case when no group is considerably larger than the other and therefore no reference group exists.

Proposition 4 (Optimality of reference groups). Firm profits are higher in the case of a promotion-based tournament than they are in a tournament where no reference group exists. Thus promotion-based tournaments dominate all the other tournament scenarios.

To prove Proposition 4 we show that if a reference group does not exist, then status concerns are detrimental to the firm because of loss aversion. This is perhaps counterintuitive since status concerns are often regarded as a cheap way of providing incentives. However, by making the identity of the winners salient, the firm can increase profits above the standard benchmark $E \Pi^{T}$ or the case where no reference group exists. Indeed, as shown above promotion-based tournaments benefit the firm by creating ego rents while eliminating status costs. Thus our model offers a rationale for the prevalence of such compensation systems as documented in Baker et al. (1988). Moreover, our results are in line with the almost complete absence of demotion-based reward schemes found in the empirical studies of Teulings and Hartog (1998).

\footnotetext{
12 Interestingly, however, effort appears to be highest when there is a balanced proportion of winner and loser prizes ( 50 percent), though not significantly higher then when the proportion of winners is large (75 percent). Harbring and Irlenbusch (2008) attribute this puzzling finding to the fact that agents may not condition their behavior on the true marginal probability of winning. Instead, they may perceive a task with a subjectively expected probability of success of $1 / 2$ as especially motivating.
} 
Finally, we formally show in Appendix A that many of our results do not depend on the relative magnitudes of $\alpha$ and $\beta$ or the sign of $\beta$. If $\beta \leq 0$ Part (i) of Proposition 1 has to be amended as equilibrium effort is lower in a promotion-based tournament than in a traditional tournament without social comparisons. However, Part ii) of Proposition 1 still holds. Finally, the main prediction of our model, that expected profits are higher in a promotion-based tournament than in a demotionbased tournament, remains unchanged even when $\beta$ is negative, as long as $\beta$ is sufficiently small in absolute value relative to $\alpha$.

\section{Promotions and demotions}

This section extends the framework studied above by introducing an additional, intermediate hierarchical level. Attention will be focused on tournaments where few workers are promoted or demoted, and the majority remain at the same hierarchical level. Our main goal will be to determine the optimal number of promotions and demotions. Thus $N_{W}$ and $N_{L}$ will be regarded as endogenous in addition to the wages.

The expected utility of the worker is now

$$
\operatorname{Pr}(i \in W)\left[w_{H}+\beta\left(w_{H}-w_{M}\right)\right]+\operatorname{Pr}(i \in M) w_{M}+\operatorname{Pr}(i \in L)\left[w_{L}+\alpha\left(w_{L}-w_{M}\right)\right]-c\left(e_{i}\right)
$$

where $i \in M$ means that worker $i$ belongs to the intermediate, neutral class and $w_{M} \in\left[w_{L}, w_{H}\right]$ is the wage the worker receives in that case. This formulation encompasses as special cases both promotion and demotion-based tournaments. Indeed, if there are no demotions $\left(N_{L}=0\right)$, then this setting reduces to a promotion-based tournament (here $w_{M}$ is the low wage), while if there are no promotions $\left(N_{W}=0\right)$, it reduces to a demotion-based tournament (here instead $w_{M}$ is the high wage). Note that implicit in (7) is the assumption that staying at the same level is the 'typical' condition: promotion and demotions are relatively rare events. ${ }^{13}$ This assumption is likely to be satisfied in practice because of switching and training costs. In Proposition 6 below we will show that it can also be justified on the basis of incentive considerations.

Let $\Delta w^{+}=w_{H}-w_{M}$ and $\Delta w^{-}=w_{M}-w_{L}$. In a symmetric equilibrium, each worker's effort solves

$$
\frac{\partial \operatorname{Pr}(i \in W)}{\partial e_{i}}(1+\beta) \Delta w^{+}-\frac{\partial \operatorname{Pr}(i \in L)}{\partial e_{i}}(1+\alpha) \Delta w^{-}=c^{\prime}(e) .
$$

Furthermore, the participation constraint (7) can be set equal to $\bar{u}$ and incorporated into the firm's profits. This yields

$$
V N e-N[\bar{u}+c(e)]+N_{W} \beta \Delta w^{+}-N_{L} \alpha \Delta w^{-} .
$$

The firm's maximization program can thus be written as to maximize (9) with respect to $\Delta w^{+}, \Delta w^{-}, N_{W}$ and $N_{L}$ subject to (8). Assuming $\partial \operatorname{Pr}(i \in W) / \partial e_{i}>0$, the incentive compatibility constraint (8) can be incorporated into firm's program. Substituting for $\Delta w^{+}$yields

$$
\max _{e, \Delta w^{-}, N_{W}, N_{L}} V N e-N[\bar{u}+c(e)]+\frac{N_{W} \beta}{\left(\partial \operatorname{Pr}(i \in W) / \partial e_{i}\right)(1+\beta)} c^{\prime}(e)+K \Delta w^{-}
$$

where $K \equiv\left[\left(\partial \operatorname{Pr}(i \in L) / \partial e_{i}\right)(1+\alpha) /\left(\partial \operatorname{Pr}(i \in W) / \partial e_{i}\right)(1+\beta)\right] N_{W} \beta-N_{L} \alpha$. A key feature of this program is that, for all $e$ and $N_{W}$, it achieves its maximum when either $\Delta w^{-}=0$ or $N_{L}=0$, or both. Note in fact that $K \leq 0$ and the relation $\partial \operatorname{Pr}(i \in L) / \partial e_{i} \leq 0$ holds with equality if $N_{L}=0$. Since it is optimal to minimize the number of demotions, program (10) reduces to a promotionbased tournament. Many of the qualitative features of this program have already been described in the previous section. Here we focus on whether it is optimal to maximize promotions (i.e. $N_{W}$ ), subject to the reference-wage constraint $N_{M} \geq N_{W}+D$. This is not a trivial question because, although it is clear that there is a beneficial effect in increasing the number of people who enjoy higher status, the effect on the incentives to exert effort must also be taken into account (in general in fact $(\partial \operatorname{Pr}(i \in W)) / \partial e_{i}$ is a function of $\left.N_{W}\right)$.

Fortunately, a simple sufficient condition can be provided to address this issue. Let agent $i$ 's probability of placing $j$ th from the bottom be denoted by $\operatorname{Pr}(i, j)$. Suppose that

$$
\frac{1}{N_{W}} \sum_{j=N-N_{W}+1}^{N} \frac{\partial \operatorname{Pr}(i, j)}{\partial e_{i}} \geq \frac{\partial \operatorname{Pr}\left(i, N-N_{W}\right)}{\partial e_{i}} .
$$

This condition states that the change in the probability of ending up at position $N_{W}+1$ from the top ( $N-N_{W}$ from the bottom) must be equal to or less than the average change in the probability of coming in at one of the first $N_{W}$ positions. This is a likely outcome if the density function of the error term is 'well-behaved'. In fact, as long as more effort increases the probability of ending up in a higher position more than in a lower position, the result holds. In particular, it is possible to show (Nalebuff and Stiglitz, 1983) that the result holds for the uniform density $f(\varepsilon)=a, \varepsilon \in[-A, A]$ and the exponential density $f(\varepsilon)=e^{\varepsilon-1}, \varepsilon \in[-\infty, 1] .{ }^{14}$

\footnotetext{
13 Formally, we assume that $N_{M} \geq D+N_{W}+N_{L}$, where $N_{M}$ is the number of worker who stay at the same level.

14 These are the distributions for which it is relatively easy to compute $(\partial \operatorname{Pr}(i \in W)) / \partial e$ as $N_{W}$ changes. In the first case, the net increase in the probability of moving in and moving out of any interior position by working harder is zero. The increase in the probability of 'winning' is concentrated in the top
} 
Proposition 5 shows that if condition (11) holds, then the firm should maximize the number of promotions, subject to the reference-wage constraint.

Proposition 5. Consider a three-prize tournament and suppose $w^{R}=w_{M}$. Under condition (11), the following conditions completely characterize the optimal structure of the tournament: (i) either $\Delta w^{-}$or $N_{L}=0$, or both, (ii) (neglecting integer problems) $N_{W}=(N-D) / 2$ and $N_{M}=(N+D) / 2$, (iii) $w_{M}$ and $w_{H}$ are set such that the workers' participation constraint binds and effort solves (10).

This result has important implications for the optimal provision of incentives in firms. The fact that it is often optimal to maximize the number of winners (subject to the reference-wage constraint) and minimize the number of losers is consistent with the empirical observation that demotions are very rare, whereas promotions are much more common (see, e.g., Baker et al., 1994a,b). It also suggests that, should there be a 'technologically right' number of promotions and demotions, which may correspond to the expected number of workers needed at higher and lower levels, demotions should be kept to the minimum (possibly by hiring new workers), whereas promotions can be expanded above that limit. Finally, the result may help explain the proliferation of job titles observed in some industries. As Baron and Bielby (1986) and Doeringer and Piore (1971) have noted, in fact, many vertical and horizontal distinctions among jobs reflect customs and status gradations and are not simply distinctions in technical duties.

It should be emphasized that Proposition 5 assumes that the reference wage is $w_{M}$. This assumption might be seen as restrictive since profits could plausibly be increased by setting a lower reference wage, $w_{L}$. The following proposition shows that this is not the case.

Proposition 6. Without loss of generality one can restrict attention to optimal tournaments in which $w^{R}=w_{M}$.

The proof of Proposition 6 establishes that optimal tournaments where $w^{R}=w_{M}$ and those where $w^{R}=w_{L}$ are equivalent (setting $w^{R}=w_{H}$ would obviously not be optimal). The intuition for this result is in part that, according to Proposition 5, the intermediate prize $w_{M}$ is actually the lowest one, since $N_{L}=0$. A more subtle point is that if $w^{R}=w_{L}$, then there would be two prizes, $w_{H}$ and $w_{M}$, above the lowest one. If we set $w^{R}=w_{M}$, instead, there would be only one. Could the added flexibility of having two prizes above the lowest one (strictly) benefit the principal? In Appendix A we show that if $w^{R}=w_{L}$, a tournament with only two prizes is optimal. This is reminiscent of Lazear (1989)'s result that in multi-prize tournaments only the highest and the lowest prize matter and all the other prizes can be chosen arbitrarily. Since this added flexibility does not strictly benefit the principal, setting $w^{R}=w_{M}$ is indeed optimal.

\section{Ambition}

The model so far has assumed that reference wages are determined only by the objective structure of the game (the tournament format). However, in reality workers' personal characteristics often play a major role. This section introduces an important source of heterogeneity among workers: ambition. We model ambition as an idiosyncratic choice of reference point, with ambitious agents setting more demanding standards for themselves. In a tournament with two prize levels, for instance, we would assume $w_{A}^{R}=w_{H}$ for ambitious workers and $w_{N A}^{R}=w_{L}$ for their unambitious colleagues, irrespective of the tournament format. ${ }^{15}$ We may think about systematic differences in ambition in terms of differences in reference groups. For instance, high ability workers may have higher reference wages because they compare themselves only with other talented individuals.

This section briefly considers how differences in ambition (or reference groups) affect equilibrium effort levels and each worker's probability of winning the contest. Several assumptions are made to keep the analysis tractable. We posit that each agent's type is public information among the agents but is unknown to the principal and that the density $g(\cdot)$ of the error difference is symmetric around its strict maximum, 0 (e.g. a normal density). More importantly, we restrict attention to tournaments where $N=2$. Thus, to focus on ambition we neglect the role that external factors such as the tournament format have in determining the reference point.

We begin by considering the case where an ambitious and an unambitious worker compete against each other. The first-order conditions for the two types are given by $\left(\partial \operatorname{Pr}(i \in W) /\left(\partial e_{A, N A}\right)\right)(1+\alpha) \Delta w=c^{\prime}\left(e_{A, N A}\right)$ and $\left(\partial \operatorname{Pr}(i \in W) / \partial e_{N A, A}\right)(1+$ $\beta) \Delta w=c^{\prime}\left(e_{N A, A}\right)$. Here $e_{i, j}, i, j \in\{A, N A\}$, denotes the effort exerted by an agent of type $i$ competing with a type $j$ worker. Note that the symmetry of the density function implies $\partial \operatorname{Pr}(i \in W) / \partial e_{A, N A}=\partial \operatorname{Pr}(i \in W) / \partial e_{N A, A}$. Thus, if losses resonate more than gains $(\alpha>\beta)$, the ambitious worker will exert more effort in equilibrium than his unambitious counterpart: $e_{A, N A}>e_{N A, A}$. This formalizes Heath et al. (1999)'s argument that "if goals act as reference points, then loss aversion implies that people who are below their goal by $x$ units will perceive their current performance as a loss relative to their goal; thus they will work harder to increase their performance by a given increment than people who are above their goal by $x$ units" (p. 85). Furthermore, ambitious workers will also have a higher chance of winning the tournament.

position, and the corresponding decrease in the probability of not winning in the bottom one. Under the exponential distribution, increasing effort equally reduces the probability of ending up in any position but the top one. Clearly, in both cases (11) holds. Nalebuff and Stiglitz (1983) use condition (11) to show the optimality of restricting prize structures to a few distinct prizes.

15 Of course, it is perfectly possible that some workers might care about status (as defined in Section 2) without being either ambitious or unambitious. 
Using this model we can rank effort levels for any given wage spread by examining the first-order conditions. We distinguish between segregated and mixed tournaments for ambitious and unambitious workers (in segregated tournaments, workers are either all ambitious or unambitious). Since the density is largest when the agents exert the same level of effort, one can easily show that segregated tournaments elicit higher equilibrium effort levels from the contestants: $e_{A, A}>e_{A, N A}$ and $e_{N A, N A}>e_{N A, A}$. Furthermore, because of loss aversion $e_{A, N A}>e_{N A, A}$. We summarize these results as follows.

Proposition 7. Ambitious workers always exert more effort in equilibrium than their unambitious colleagues when paired together. Furthermore, both types exert more effort in a segregated tournament than in a mixed setting. Therefore $e_{A, A}>$ $e_{A, N A}, e_{N A, N A}>e_{N A, A}$.

Proposition 7 may help explain some of the conclusions of Gneezy et al. (2003) who find marked gender differences in performance when comparing individuals' responses to different types of incentives. Using experimental evidence of a simple maze game they show that women are less successful than men in mixed competitive environments (e.g., tournaments), even though they are able to perform as well as men in noncompetitive environments (e.g. piece-rate schemes) or segregated competitive environments. If one is willing to assume that women are less ambitious (i.e., set lower reference wages for themselves) than men (see, for example, Clark, 1997; Falk and Knell, 2004; Huberman et al., 2004) our model offers an explanation for why women may exert less effort and compete less fiercely than men in mixed tournaments. In particular, if women are assumed to be less ambitious than men our model predicts that (1) in a mixed competitive environment women should exert less effort and perform worse than men $\left(e_{A, N A}>e_{N A, A}\right)$ and that (2) women should also perform better in a segregated than in a mixed competitive environment $\left(e_{N A, N A}>e_{N A, A}\right)$. These predictions are in line with the experimental evidence of Gneezy et al. (2003) and our model coupled with the assumption of gender differences in ambition thus offers one possible explanation for their puzzling findings. Furthermore, Gneezy et al. (2003) also find some evidence that men perform better than women when both are placed in segregated competitive environments and this finding is also in line with another of our theoretical predictions $\left(e_{A, A}>e_{N A, N A}\right){ }^{16}$

\section{Ambition and ability}

This section extends the model in Section 4 by allowing workers to differ not only in ambition but also in ability. The production technology is now given by $x_{i}=a_{i}+e_{i}+\varepsilon_{i}$ where $a_{i}$ denotes agent $i$ 's intrinsic ability and is public information among the agents but unknown to the principal. Here ability enters additively in the production function so that the marginal return to effort does not vary with ability. We assume that $a_{i}$ takes the values $\left\{a_{L}, a_{H}\right\}$ with $a_{H}-a_{L}=a>0$. That is, agents can either be of low or high ability.

\subsection{Correlation between ambition and ability}

To study the role of correlation between ability and ambition, we consider a tournament scenario where agents are paired at random from a pool of workers who are differentiated along these two dimensions. Note that since the agents' types are unknown to the principal, the wage spread $\Delta w$ must be the same irrespective of the identity of the contestants. There are equal shares of ambitious and unambitious workers, $\operatorname{Pr}(A)=\operatorname{Pr}(N A)$ and we further assume that the conditional probabilities that a worker is of high (low) ability given that he is ambitious (unambitious) are given by $p=\operatorname{Pr}(H \mid A)=\operatorname{Pr}(L \mid N A)$. When $p=1$ ambition and ability are perfectly positively correlated, so that all ambitious workers are more able than the unambitious workers. Conversely, the two dimensions are perfectly negatively correlated when $p=0$ and uncorrelated when $p=1 / 2$. The next proposition establishes how the correlation between ambition and ability influences effort levels and the selection of able workers.

Proposition 8. In any equilibrium the ambitious worker exerts more effort than the unambitious worker in the same tournament. The probability of promoting an able worker is strictly increasing in the correlation between ability and ambition. Moreover, if $c^{\prime \prime \prime}(\cdot) \leq 0$, then average effort is lower when ability and ambition are perfectly positively correlated than when they are perfectly negatively correlated. ${ }^{17}$

In our setting both ambition and ability increase the probability of promotion. So it is not surprising that the probability of promoting an able worker increases with the correlation between ability and ambition. However, Proposition Proposition 8 also highlights that if one worker is both more ambitious and of higher ability than his competitor, the odds are heavily stacked in his favour. Thus a possible drawback of positive correlation is that it may induce low effort levels from both contestants.

\footnotetext{
16 There is also a large empirical literature concerning gender differences in wages and promotion rates that, with some exceptions, finds lower wages and promotion rates for women (see, e.g., Ransom and Oaxaca, 2005; Blau and DeVaro, 2007). Several papers try to disentagle whether these differences are due to productivity or female preferences for different types of jobs or due to discrimination. If one assumes gender differences in ambition our model predicts that women exert less effort than men in mixed gender environments and thus it offers one possible explanation for why women are less likely to be promoted than otherwise observationally similar men. However, this explanation may not be entirely independent of discrimination since women could be less ambitious because of a general milieu of discrimination or social pressures.

17 Condition $c^{\prime \prime \prime}(\cdot) \leq 0$ includes as a special case the quadratic cost of effort. More generally, requiring $c^{\prime}$ to be 'not too convex' would suffice.
} 
An interesting implication of our analysis is that tournament promotion systems might not be as ineffective as a selection device as previously thought. Baker et al. (1988, p. 602), for instance, claim that "tournament promotions systems cannot in general match employees to the jobs for which they are best suited" since performance in the current job might not be the best indicator of performance in another job. What our model highlights is that, if the more able workers choose to compare themselves to equally able workers and not to low ability workers as the evidence suggests, promotion inefficiencies may be reduced. ${ }^{18}$

\subsection{Managing diversity in the workplace}

We now demonstrate that our framework can also usefully be applied to important problems in human resources management. Specifically, we extend our previous analysis to consider a setting where the firm can learn a worker's type, in particular the worker's ambition level. A question that naturally arises in such a setting is how the firm should mix and match its workers according to their personality traits. ${ }^{19}$

There are four contestants, two ambitious workers and two unambitious workers and the firm simultaneously runs two promotion tournaments. In the first stage, the firm designs a tournament $\left(w_{H}, w_{L}\right)$ where contestants compete in pairs and the contestant that produces the most output in each of the two tournaments is promoted and receives $w_{H}$ while the loser receives $w_{L}$. We denote by $T>0$ the additional profits that accrue to the firm when a talented worker is promoted. In the second stage, the firm observes the workers' ambition level and decides how to match the four contestants. ${ }^{20}$ In the third stage, the workers observe their own ambition and ability levels and those of their respective opponent and then exert effort. Finally, output is realized, and promotion decisions are made. As before we assume that the conditional probabilities that a worker is of high (low) ability given that he is ambitious (unambitious) are $p=\operatorname{Pr}(H \mid A)=\operatorname{Pr}(L \mid N A)$ so that ambition and ability are perfectly positively correlated if $p=1$, they are perfectly negatively correlated when $p=0$ and uncorrelated when $p=1 / 2$. In other words, when $p \neq 1 / 2$ ambition is an informative signal of ability.

In such a situation, it is natural to ask whether the firm should mix ambitious and unambitious contestants or whether it should match similar types of workers? In other words, should the tournaments be mixed - each unambitious worker is paired with an ambitious worker - or segregated - each (un)ambitious worker is paired with the other (un)ambitious worker? It is important to note that the matching of similar types creates stronger incentives for effort. Equilibrium effort is maximized when contestants are evenly matched since the density function $g$ achieves its maximum at 0 . Thus, the manager will only prefer mixed tournaments to segregated tournaments when mixing is beneficial in terms of selection. The next proposition summarizes our main result.

Proposition 9. (i) Average effort is higher in segregated tournaments than in mixed tournaments. The benefits of promotion can be higher in either organization of tournaments. (ii) If $p=0$, mixed tournaments are optimal when selection is important ( $T$ is large) and the ability gap a is sufficiently large relative to the difference in ambition levels $\alpha-\beta$. (iii) If $p=1$, mixed tournaments are optimal when selection is sufficiently important (T is sufficiently large).

The intuition for Proposition 9 is the following. Average effort is higher in segregated tournaments than in mixed tournaments since in segregated tournaments the firm creates a more even playing field between the contestants. There are two forces that work in favour of segregated tournaments with respect to average efforts. First, segregated tournaments match together contestants of equal ambition levels thus creating stronger incentives for effort than mixed tournaments where contestants have different ambition levels. Second, the stronger the (positive or negative) correlation between ambition and ability, i.e. the closer $p$ is to 0 or to 1 , the more likely it is that two workers that share the same ambition level will also share the same ability level. This further evens the contest in a segregated tournament and thus increases incentives for effort. Only if the ambition levels of ambitious and unambitious workers are identical, $\alpha=\beta$, (thus eliminating the first advantage of segregated tournaments) and ambition and ability are uncorrelated, $p=1 / 2$, (thus eliminating the second advantage) do mixed tournaments perform as well as segregated tournaments in terms of average effort. Obviously, since segregated tournaments always lead to higher effort, it has to be the case that selection motives are very important ( $T$ is large) if mixed tournaments are preferred.

The choice between tournaments is less clear when considering the benefits of promotion. Depending on parameter values either segregated or mixed tournaments could be better. The trade-off in terms of selection can be clearly illustrated

\footnotetext{
${ }^{18}$ For instance, Falk and Knell (2004) show that students with higher intellectual abilities choose higher reference standards, thus effectively comparing themselves to similar others.

19 We are grateful to an anonymous Associate Editor for suggesting this under-researched question. Lazear (1989) also explores a related analysis of personality traits when sabotage is possible, but agents may have a preference for cooperative behavior.

${ }^{20}$ We make two important assumptions. The first assumption is that there is diversity: workers of different types are willing to accept the contract $\left(w_{H}, w_{L}\right)$. This would be the case, for instance, if search costs are high enough to induce the firm to offer high wages or reservation wages are stochastic. Here, we simply assume that workers only learn their type after accepting the contract. The second assumption is that the manager is not allowed to change the prize structure $\left(w_{H}, w_{L}\right)$ in response to new information about the workers' types. This form of wage rigidity could easily be justified in terms of communication or administrative costs and is, we believe, quite reasonable. The key analytical advantage of this assumption is that it facilitates the comparison across tournament scenarios because the wage bill is fixed.
} 
in the case where ambition and ability are uncorrelated, $p=1 / 2$. Segregated tournaments are preferred in terms of selection if

$$
2 G(a)>G\left(a+\Delta_{1}\right)+G\left(a-\Delta_{3}\right)
$$

where $\Delta_{1}=e_{A, N A}^{H, L}-e_{N A, A}^{L, H}>0$ and $\Delta_{3}=e_{A, N A}^{L, H}-e_{N A, A}^{H, L}>0$. The left-hand side denotes the probability that an able worker is promoted in the each of the two segregated tournaments. In each segregated tournament, the contestants exert equal efforts and hence the probability that an able contestant is promoted is exactly $G(a)$. In a mixed tournament the contestants have different ambition levels and therefore exert different effort. The probability that a talented worker is promoted is $G\left(a+\Delta_{1}\right)>G(a)$ when the ambitious worker is more talented and the unambitious worker is less talented. In this case, ambition and ability work hand in hand and make it more likely that the more talented worker is promoted. In contrast, the probability of promoting a talented worker is $G\left(a-\Delta_{3}\right)<G(a)$ if the ambitious worker is less talented than the unambitious worker since here talent and ambition work in opposite directions.

When talent and ambition are perfectly positively correlated, talented individuals are also likely to be ambitious and therefore win mixed tournaments more often than not. They enjoy an ability advantage and also exert more effort than their less ambitious opponent. As a result, mixing ambitious and unambitious workers then always increases the chances of promoting the more able worker relative to matching similar workers. If $T$ is large enough, this selection effect can compensate the lower equilibrium effort relative to segregated tournaments. Mixed tournaments need not be better than segregated tournaments in terms of selection. While it is true that, ceteris paribus, more able workers are more likely to win tournaments due to their ability advantage, when talent and ambition are negatively correlated, it is not necessarily the case that in mixed tournaments more talented but less ambitious workers perform better on average than their less talented but more ambitious counterparts. This is because the ambitious contestants may exert high effort in equilibrium so as to fully compensate their ability disadvantage. Indeed, when ambition and ability are negatively correlated, for mixed tournaments to be better in terms of selection than segregated tournaments the ability gap $a$ has to be sufficiently large relative to the difference in ambition $\alpha-\beta$, since this means that the difference in effort levels between contestants of different ambition levels will not be able to outweigh their difference in ability levels. Therefore, as Proposition 9 makes clear, the conditions that ensure the optimality of mixed tournaments tend to be more restrictive under perfectly negative correlation than under perfectly positive correlation.

The implications of Proposition 9 for managing diversity in the workplace can be important. As mentioned before women, on average, are less status-seeking than men and hence despite high ability and talent may fail to scale the corporate ladder. For example, only 11.7 percent of FTSE 100 directors are women, but Hewitt (2003) claims that "diversity in the boardroom goes hand in hand with good corporate governance, better customer relations, and ultimately, is beneficial to the bottom line." This claim is in line with our previous argument according to which women might not make it to the top of the organization due to a lack of status concerns and ambition, but companies would nonetheless benefit from promoting the most able worker ( $T$ is large). Favourable promotion quotas for female workers might therefore improve the trade-off between incentive provision and efficient promotion decisions. In terms of our model, female workers would effectively be placed into single-sex segregated tournament in which they would compete more intensely and the most able among them would be promoted.

\section{Concluding remarks}

A large body of evidence suggests that there is a human tendency to compare outcomes with others and that individuals are often more motivated by the desire to avoid losses than they are by maximizing gains. The contribution of this paper has been to introduce such status concerns in an otherwise standard tournament model and to show that this incorporation has interesting implications for the optimal provision of incentives.

Similar to previous contributions we found that status considerations enhance incentives for effort and that a firm can benefit from such status considerations through the provision of lower monetary incentives. However, since our paper considered contests with more than two agents we were able to show that the choice of the tournament format is not neutral. A firm is better off choosing tournaments that reward winners instead of tournaments that penalize losers. This result may indeed be initially surprising since for a given wage spread demotion-based tournaments actually provide stronger incentives for effort. Our finding is particularly important since to our knowledge it is the first rigorous explanation for the prevalence of promotion-based systems and for the almost complete absence of demotion-based reward schemes documented in several empirical studies. Our setup is quite robust to changes in the parameters that capture status preferences. It also allowed us to show that our results apply more generally, in particular to settings where the firm is also free to choose the number of demotions and promotions in addition to choosing the wage levels. The finding that a firm will want to minimize the number of demotions and maximize the number of promotions (subject to a reference-wage constraint) also chimes well with the phenomenon of job title proliferation often observed in organizations.

In the second part of the paper we extended the analysis to allow for differences in ambition and showed that such differences could explain the differential effort and performance of men and women in mixed and segregated competitive environments as well as offer one explanation for the observed gender wage and promotion rate gap without invoking discrimination or differences in ability or in outside opportunities. We analyzed the role of differential ability levels of 
workers and its interaction with ambition. In contrast to previous contributions which claim that tournaments cannot in general match employees to the jobs for which they are best suited, we showed that the adverse consequences of using tournaments as a sorting device could be small, particularly when ambition and ability are positively correlated. However, we also showed that the positive correlation between ability and ambition may be a double-edged sword since is also leads to lower effort supply. Finally, we applied our model to study the question of diversity in the workplace and showed that although organizations only want to mix contestants when the benefits of selecting the more able employees are sufficiently important to compensate for the resulting drop in equilibrium effort, in some situations segregated tournaments may also improve selection.

Our analysis has left a number of interesting questions open. For instance, while our model focuses on promotions and demotions, one may wish to consider $n$-prize tournaments. We expect that most if not all of our results would carry over to this more general set-up. Although in Sections 4 and 5 we explore how heterogeneous agents compete, we do not analyze how the principal's profit varies between the different forms of tournaments explored in Sections 2 and 3 under contestant heterogeneity. In particular, which types of workers receive surplus in an equal-treatment tournament and what are the conditions under which workers choose to self-select into the tournaments designed for them? For example, do low-ambition workers prefer to join firms with other low-ambition workers or do they prefer to mix with high-ambition work colleagues? Do firms then have an incentive of fostering a "common culture" where everyone in the organization has similar preferences or a "culture of diversity" where workers are different? A third issue is that our discussion mainly relates to promotion as the outcome of the tournament. This was motivated by the fact that in practice the results of a tournament are more visible than higher pay due to pay secrecy, and that therefore interpersonal comparisons are more likely to matter in the former case. However, it is not obvious that this needs to be the case if, for instance, the firm announces all the wages publicly. How firms should choose between different degrees of disclosure and secrecy in wage setting in order to maximize workers' incentives to work hard and to minimize the impact of competing wage offers for the successful employees by other employers is, in our view, a promising avenue for subsequent studies. We leave the exploration of these issues to future research.

\section{Acknowledgements}

We are particularly indebted to Meg Meyer for her invaluable support and comments and Klaus Schmidt for his guidance at an early stage of the paper. We also would like to thank Heski Bar-Isaac, Stefano DellaVigna, Alex Edmans, Xavier Gabaix, Robert Gibbons, David Gill, Bengt Holmstrom, Ian Jewitt, David Laibson, Heikki Rantakari, Julia Simon-Kerr, two referees, an anonymous Associate Editor, the Editor, and seminar audiences at MIT, Oxford, Rotterdam and at the EEA-ESEM 2006 meetings in Vienna for helpful discussions and remarks, as well as the Seminar for Economic Theory at the University of Munich for its hospitality. Financial support from Nuffield College, ESRC, the European Commission's Marie Curie Fellowship Programme and the British Academy is gratefully acknowledged. All remaining errors are ours.

\section{Appendix A. Omitted proofs}

We begin with a lemma which is useful to prove Propositions 1 and 3.

Lemma 1. Consider a tournament with $N$ contestants and $N_{W}$ winners. Let $\operatorname{Pr}\left(i \in W \mid N_{W}\right)$ denote the probability that agent $i$ is a winner. In a symmetric equilibrium $\partial \operatorname{Pr}\left(i \in W \mid N_{W}\right) / \partial e_{i}$ is independent of the overall level of effort.

Proof of Lemma A.1. Let $\operatorname{Pr}(i, j)$ denotes contestant $i$ 's probability of placing $j$ th from the bottom. This probability is given by $\operatorname{Pr}(i, j)=\{[(N-1) !] /[(N-j) !(j-1) !]\} \int F\left(e_{i}-e^{*}+\varepsilon_{i}\right)^{j-1}\left[1-F\left(e_{i}-e^{*}+\varepsilon_{i}\right)\right]^{N-j} f\left(\varepsilon_{i}\right) d \varepsilon_{i}$ where $e^{*}$ denotes the equilibrium effort level of the other agents and the integral is taken on the entire support of $\varepsilon_{i}$. At the symmetric equilibrium $\left(e_{i}=e^{*}\right)$, agent $i$ has an equal chance of ending up in any position and therefore $\operatorname{Pr}\left(i \in W \mid N_{W}\right)=N_{W} / N$. By working harder at the symmetric equilibrium there is an increased (or decreased) chance of coming in at position $j: \partial \operatorname{Pr}(i, j) / \partial e_{i}=\{[(N-1) !] /[(N-j) !(j-1) !]\} \int F\left(\varepsilon_{i}\right)^{j-2}\left[1-F\left(\varepsilon_{i}\right)\right]^{N-j-1} f\left(\varepsilon_{i}\right)^{2}\{(j-$ $\left.1)\left[1-F\left(\varepsilon_{i}\right)\right]-(N-j) F\left(\varepsilon_{i}\right)\right\} d \varepsilon_{i}$. Since $\operatorname{Pr}\left(i \in W \mid N_{W}\right)=\sum_{j=N-N_{W}}^{N} \operatorname{Pr}(i, j), \quad \partial \operatorname{Pr}\left(i \in W \mid N_{W}\right) / \partial e_{i}=\sum_{j=N-N_{W}+1}^{N}\{[(N-1) !] /[(N-$ $j) !(j-1) !]\} \int F\left(\varepsilon_{i}\right)^{j-2}\left[1-F\left(\varepsilon_{i}\right)\right]^{N-j-1} f\left(\varepsilon_{i}\right)^{2}\left\{(j-1)\left[1-F\left(\varepsilon_{i}\right)\right]-(N-j) F\left(\varepsilon_{i}\right)\right\} d \varepsilon_{i}$. Inspection of this equation shows that $\partial \operatorname{Pr}\left(i \in W \mid N_{W}\right) / \partial e_{i}$ is independent of the level of effort $e^{*}$.

Proof of Proposition 3. In the benchmark case without status concerns, equilibrium effort is given by the familiar condition $V=c^{\prime}\left(e^{T}\right)$. In promotion-based and demotion-based tournaments, we have instead

$$
\begin{aligned}
& V+\frac{N_{W}^{P B}}{N} \frac{\beta}{1+\beta}\left(\frac{\partial \operatorname{Pr}\left(i \in W \mid N_{W}^{P B}\right)}{\partial e_{i}}\right)^{-1} c^{\prime \prime}\left(e^{P B}\right)=c^{\prime}\left(e^{P B}\right) \\
& V-\frac{N-N_{W}^{D B}}{N} \frac{\alpha}{1+\alpha}\left(\frac{\partial \operatorname{Pr}\left(i \in W \mid N_{W}^{D B}\right)}{\partial e_{i}}\right)^{-1} c^{\prime \prime}\left(e^{D B}\right)=c^{\prime}\left(e^{D B}\right) .
\end{aligned}
$$


Since the cost function is convex and $\left(\partial \operatorname{Pr}\left(i \in W \mid N_{W}\right)\right) / \partial e_{i}>0$ is independent of the overall level of $e$ (see Lemma A.1), it follows that $e^{P B}>e^{T}>e^{D B}$.

Proof of Proposition 4. If no reference group exists, the number of winners $N_{W}^{N R}$ must be such that $N_{W}^{N R} \in\left(N_{L}^{N R}-D, N_{L}^{N R}+D\right)$. Then the reference wage is $(1 / N) \sum_{i=1}^{N} w_{i}$ and expected profits are $E \Pi^{N R}=V N e-N[\bar{u}+c(e)]-$ $(\alpha-\beta)\left(w_{H}-w_{L}\right)\left(N_{W}^{N R}\left(N-N_{W}^{N R}\right)\right) / N$. Clearly for all $e, E \Pi^{P B}(e)>E \Pi^{N R}(e)$. From Proposition 2 we also know that $E \Pi^{P B}(e)>$ $E \Pi^{D B}(e)$ and that these rankings are preserved when effort levels are chosen optimally. Proposition 4 follows.

\section{A.1. Robustness with respect to magnitudes of $\alpha$ and $\beta$ and sign of $\beta$}

We now show how our results change when we modify our assumptions about the relative magnitudes of $\alpha$ and $\beta$ or the sign of $\beta$. First, if $\beta \leq 0$ Part (i) of Proposition 1 has to be amended. Indeed, from Lemma A.1 and Eqs. (4b) and (5b) it then follows that equilibrium effort is lower in a promotion-based tournament than in a traditional tournament without social comparisons. Second, if $\beta \leq 0$ Part (ii) of Proposition 1 still holds. This follows from Lemma A.1, Eqs. (5b) and (6b), and the fact that $\alpha-\beta$ is now larger. Third, even if $\beta \leq 0$ expected profits are higher in a promotion-based tournament than in a demotion-based tournament provided $\beta$ is sufficiently small in absolute value relative to $\alpha$. Indeed, Eqs. (5a) and (6a) imply that for all $e$ and $|\beta|$ small, $E \Pi^{P B}(e)>E \Pi^{D B}(e)$. Let $e^{P B}$ and $e^{D B}$ denote, respectively, the effort levels that solve (5a) and (6a). Then $E \Pi^{P B}\left(e^{P B}\right) \geq E \Pi^{P B}\left(e^{D B}\right)>E \Pi^{D B}\left(e^{D B}\right)$, where the first inequality follows from the definition of optimality and the second from the relationship between $E \Pi^{P B}(e)$ and $E \Pi^{D B}(e)$.

Proof of Proposition 5. In Section 3 we showed that it is optimal for the firm to minimize the number of demotions by setting either $\Delta w^{-}$or $N_{L}$ equal to zero, or both. This implies that the firm's program (10) reduces to

$$
\max _{e, N_{W}} \Pi\left(e, N_{W}\right)=V N e-N[\bar{u}+c(e)]+N_{W} \frac{\beta}{1+\beta}\left(\frac{\partial \operatorname{Pr}\left(i \in W \mid N_{W}\right)}{\partial e_{i}}\right)^{-1} c^{\prime}(e)
$$

which is the same expression that one would obtain in a promotion-based tournament. Here we show that provided (11) holds, it is also optimal to maximize the number of promotions $N_{W}$ subject to $w_{M}$ being the typical wage (this requires $\left.N_{M} \geq N_{W}+N_{L}+D\right)$. A sufficient condition for this to be true is that $\Pi\left(e, N_{W}+1\right) \geq \Pi\left(e, N_{W}\right) \Leftrightarrow\left(N_{W}+\right.$ $1) /\left(\partial \operatorname{Pr}\left(i \in W \mid N_{W}+1\right) / \partial e_{i}\right) \geq N_{W} /\left(\partial \operatorname{Pr}\left(i \in W \mid N_{W}\right) / \partial e_{i}\right)$ for all $\left.N_{W}=1,2, \ldots, \mid(N-D) / 2\right\rfloor$. This last condition can be rewritten as $1 / N_{W} \partial \operatorname{Pr}\left(i \in W \mid N_{W}\right) / \partial e_{i} \geq \partial \operatorname{Pr}\left(i \in W \mid N_{W}+1\right) / \partial e_{i}-\partial \operatorname{Pr}\left(i \in W \mid N_{W}\right) / \partial e_{i}$, which, since $\operatorname{Pr}\left(i \in W \mid N_{W}\right)=\sum_{j=N-N_{W}}^{N} \operatorname{Pr}(i, j)$, is equivalent to (11). Thus, if (11) holds, the firm has an incentive to always increase the number of promotions subject to $N_{M} \geq N_{W}+N_{L}+D$. Proposition 5 then easily follows.

Proof of Proposition 6. We begin by showing that in a three-prize tournament the firm always chooses to create a reference group. Then we prove that setting $w^{R}=w_{M}$ is optimal.

For any given reference wage $w^{R} \in\left[w_{L}, w_{H}\right]$, the expected utility of a worker is given by $\operatorname{Pr}(i \in W)\left[w_{H}+\beta\left(w_{H}-w^{R}\right)\right]+$ $\operatorname{Pr}(i \in M)\left[w_{L}+z\left(w_{M}-w^{R}\right)\right]+\operatorname{Pr}(i \in L)\left[w_{L}+\alpha\left(w_{L}-w^{R}\right)\right]-c\left(e_{i}\right)$ where $z=\alpha$ if $w_{M} \leq w^{R}$, and $z=\beta$ if $w_{M}>w^{R}$. Since in equilibrium all agents exert the same level of effort and the participation constraint binds, expected profits can be written as

$$
E \Pi^{N R}=V N e-N[\bar{u}+c(e)]+\beta N_{W}\left(w_{H}-w^{R}\right)+z N_{M}\left(w_{M}-w^{R}\right)+\alpha N_{L}\left(w_{L}-w^{R}\right) .
$$

Note that $E \Pi^{T} \geq E \Pi^{N R}$ is equivalent to $\beta N_{W}\left(w_{H}-w^{R}\right)+z N_{M}\left(w_{M}-w^{R}\right)+\alpha N_{L}\left(w_{L}-w^{R}\right) \leq 0$ (recall that $E \Pi^{T}$ denotes expected profits in the traditional case where $\alpha=\beta=0)$. Let $n_{j}=N_{j} / N, j=W, M, L$ and $\Delta w_{r k}=w_{r}-w_{k}, r, k=H, M, L$. After some manipulations, $E \Pi^{T} \geq E \Pi^{N R}$ yields $(\alpha-\beta) n_{L} n_{W} \Delta w_{H L}+(\alpha-z) n_{L} n_{M} \Delta w_{M L}+(z-\beta) n_{M} n_{W} \Delta w_{H M} \geq 0$. This inequality is always verified since $\alpha>\beta$. Thus setting $w^{R}=1 / N \sum_{i}^{N} w_{i}$ cannot be optimal since the firm can do strictly better by choosing a promotion-based tournament (indeed, $E \Pi^{P B} \geq E \Pi^{T}$ ). Hence the firm will always create a reference group.

Next, we show that setting $w^{R}=w_{M}$ is optimal. Consider the case where $w^{R}=w_{L}$ (setting $w^{R}=w_{H}$ is clearly suboptimal). At the symmetric equilibrium, each worker's effort solves $\left(\partial \operatorname{Pr}(i \in W) / \partial e_{i}\right)(1+\beta) \Delta w^{+}-\left(\partial \operatorname{Pr}(i \in L) / \partial e_{i}\right)(1+$ $\beta) \Delta w^{-}=c^{\prime}(e)$, where $\Delta w^{+}=w_{H}-w_{M}$ and $\Delta w^{-}=w_{M}-w_{L}$. Furthermore, because the participation constraint binds, $N_{W} w_{H}+N_{L} w_{L}+N_{M} w_{M}=N[\bar{u}+c(e)]-N_{W} \beta\left(w_{H}-w_{L}\right)-N_{M} \beta\left(w_{M}-w_{L}\right)$. The firm therefore maximizes $V N e-N[\bar{u}+c(e)]+$ $N_{W} \beta \Delta w^{+}+\left(N_{W}+N_{M}\right) \beta \Delta w^{-}$with respect to $\Delta w^{+}, \Delta w^{-}, N_{W}, N_{L}$, subject to the incentive compatibility constraint. Provided $\partial \operatorname{Pr}(i \in W) / \partial e_{i}>0$, this program can be written as

$$
\max _{e, \Delta w^{-}, N_{W}, N_{L}} V N e-N[\bar{u}+c(e)]+\frac{\beta}{1+\beta} \frac{N_{W} c^{\prime}(e)}{\frac{\partial \operatorname{Pr}(i \in W)}{\partial e_{i}}}+A \beta \Delta w^{-}
$$

where $A \equiv\left[1+\left(\partial \operatorname{Pr}(i \in L) / \partial e_{i}\right) /\left(\partial \operatorname{Pr}(i \in W) / \partial e_{i}\right)\right] N_{W}+N_{M}$. Note that for any given $N_{W}, N_{L}, e, A$ is a constant. There are three possibilities: either $A>0, A<0$ or $A=0$. In the first case, it is clearly optimal to maximize $\Delta w^{-}$subject to $w_{M} \in\left[w_{L}, w_{H}\right]$ and therefore $w_{M}=w_{H}$. If $A<0$, instead, it is optimal to set $w_{M}=w_{L}$. If $A=0$ any $w_{M}$ would do, and in particular $w_{M}=w_{H}$ or $w_{M}=w_{L}$. Thus, without loss of generality, if $w^{R}=w_{L}$ we can restrict attention to a tournament with only two prizes where 
the lowest wage is the reference wage. This is precisely the definition of a promotion-based tournament. We also know that if $w^{R}=w_{M}$, then it is optimal to set $N_{L}=0$ and create a promotion-based tournament (Proposition 5). Thus equilibrium profits when $w^{R}=w_{M}$ must be the same as when $w^{R}=w_{L}$. Setting $w^{R}=w_{M}$ is therefore optimal.

Proof of Proposition 7. The first-order conditions for effort with equal prize spreads are as follows: $g(0)(1+\alpha) \Delta w=$ $c^{\prime}\left(e_{A, A}\right)$ in segregated tournament with only ambitious workers; $g(0)(1+\beta) \Delta w=c^{\prime}\left(e_{N A, N A}\right)$ in segregated tournament with only unambitious workers; and $g\left(e_{A, N}-e_{N A, A}\right)(1+\alpha) \Delta w=c^{\prime}\left(e_{A, N A}\right)$ and $g\left(e_{A, N A}-e_{N A, A}\right)(1+\beta) \Delta w=c^{\prime}\left(e_{N A, A}\right)$ in mixed tournament, for ambitious and unambitious workers, respectively. Since the density $g$ achieves its strict maximum at 0 , $e_{A, A}>e_{A, N A}$ and $e_{N A, N A}>e_{N A, A}$. Furthermore, as shown in the main text, $e_{A, N A}>e_{N A, A}$ because of loss aversion. This proves Proposition 7.

Proof of Proposition 8. Let equilibrium effort levels be denoted by $e_{i, j}^{k, h}$ where $i, j \in\{N A, A\}$ and $k, h \in\{L, H\}$. Thus $e_{i, j}^{k, h}$ is the effort exerted by an agent of type $(i, k)$ competing with a type $(j, h)$ worker. We consider the case of perfectly positive and negative correlation between ambition and ability (the case when workers are equally able has been studied in Section 4). From the first-order conditions the following relations for equilibrium effort are obtained:

$$
\begin{aligned}
& g\left(a+e_{A, N A}^{H, L}-e_{N A, A}^{L, H}\right)(1+\alpha) \Delta w=c^{\prime}\left(e_{A, N A}^{H, L}\right) \\
& g\left(e_{N, H}^{L, H}-e_{A, N A}^{H, L}-a\right)(1+\beta) \Delta w=c^{\prime}\left(e_{N A, A}^{L, H}\right) \\
& g\left(e_{A, N A}^{L, H}-e_{N A, A}^{H, L}-a\right)(1+\alpha) \Delta w=c^{\prime}\left(e_{A, H A}^{L, H}\right) \\
& g\left(a+e_{N A, A}^{H, L}-e_{A, N A}^{L, H}\right)(1+\beta) \Delta w=c^{\prime}\left(e_{N A, A}^{H, L}\right) .
\end{aligned}
$$

For instance, the first two equations define equilibrium effort levels when an ambitious and high ability worker is paired in a tournament with an ambitious, low ability worker. We begin by showing that ambitious workers exert more effort than their unambitious counterparts in the same tournament: $e_{A, N A}^{L, H}>e_{N A, A}^{H, L}$ and $e_{A, N A}^{H, L}>e_{N A, A}^{L, H}$. We already know from Section 4 that $e_{A, N A}^{L, L}>e_{N A, A}^{L, L}$ and $e_{A, N A}^{H, H}>e_{N A, A}^{H, H}$. Since the density function $g(\cdot)$ is symmetric around zero, $g\left(a+e_{A, N A}^{H, L}-e_{N A, A}^{L, H}\right)=g\left(e_{N A, A}^{L, H}-\right.$ $\left.e_{A, N A}^{H, L}-a\right)$ and $g\left(e_{A, N A}^{L, H}-e_{N A, A}^{H, L}-a\right)=g\left(a+e_{N A, A}^{H, L}-e_{A, N A}^{L, H}\right)$. The above first-order conditions and ambition differences $(\alpha>\beta)$ then imply $e_{A, N A}^{H, L}>e_{N A, A}^{L, H}$ and $e_{A, N A}^{L, H}>e_{N A, A}^{H, L}$.

Next, we show that the probability of promoting an able worker is strictly increasing in the correlation between ability and ambition. When drawing and pairing two workers at random the probability that an able worker is promoted is

$$
\Lambda=\frac{1}{4}+\frac{1}{2} p^{2} G\left(e_{A, N A}^{H, L}-e_{N A, A}^{L, H}+a\right)+\frac{1}{2}(1-p)^{2} G\left(e_{N A, A}^{H, L}-e_{A, N A}^{L, H}+a\right)+p(1-p) G(a)+0
$$

Differentiating this expression with respect to $p$ yields

$$
\frac{d \Lambda}{d p}=p\left[G\left(e_{A, N A}^{H, L}-e_{N A, A}^{L, H}+a\right)-G(A)\right]+(1-p)\left[G(a)-G\left(e_{N A, A}^{H, L}-e_{A, N A}^{L, H}+a\right)\right]>0
$$

since $G\left(e_{A, N A}^{H, L}-e_{N A, A}^{L, H}+a\right)>G(a)>G\left(e_{N A, A}^{H, L}-e_{A, N A}^{L, H}+a\right)$ for all $p \in[0,1]$. Thus the probability of promoting an able worker is strictly increasing in the correlation parameter $p$.

Finally, we show that if $c^{\prime \prime \prime}(\cdot) \leq 0$, then average effort is lower when ability and ambition are perfectly positively correlated than when they are perfectly negatively correlated. The difference in average efforts exerted when $p=1$ and when $p=0$ is given by

$$
\left.E\left[\sum_{i=1,2} e_{i}\right]\right|_{p=1}-\left.E\left[\sum_{i=1,2} e_{i}\right]\right|_{p=0}=\frac{1}{2}\left[e_{A, N A}^{H, L}+e_{N A, A}^{L, H}-e_{N A, A}^{H, L}-e_{A, N A}^{L, H}\right] .
$$

Thus it suffices to show that $c^{\prime \prime \prime} \leq 0$ implies $e_{A, N A}^{L, H}>e_{A, N A}^{H, L}$ and $e_{N A, A}^{H, L}>e_{N A, A}^{L, H}$.

¿From the first-order conditions it follows that $e_{A, N A}^{L, H}>e_{A, N A}^{H, L} \Leftrightarrow g\left(\Delta_{3}-a\right)>g\left(a+\Delta_{1}\right)$ where $\Delta_{3} \equiv e_{A, N A}^{L, H}-$ $e_{N A, A}^{H, L}>0$ and $\Delta_{1} \equiv e_{A, N A}^{H, L}-e_{N A, A}^{L, H}>0$. Since $g(\cdot)$ is single-peaked around 0 and $a>0, g\left(\Delta_{3}-a\right)>g\left(a+\Delta_{1}\right)$ implies $\Delta_{3}-a \in\left(-a-\Delta_{1}, a+\Delta_{1}\right)$. Obviously $\Delta_{3}-a>-a-\Delta_{1}$. Now suppose by contradiction that $\Delta_{3}-a \geq a+\Delta_{1}$. Rearranging the first-order conditions one obtains $\Delta_{1}=h\left(g\left(a+\Delta_{1}\right)(1+\alpha) \Delta w\right)-h\left(g\left(a+\Delta_{1}\right)(1+\beta) \Delta w\right)$ and $\Delta_{3}=$ $h\left(g\left(\Delta_{3}-a\right)(1+\alpha) \Delta w\right)-h\left(g\left(\Delta_{3}-a\right)(1+\beta) \Delta w\right)$, where $h \equiv\left(c^{\prime}\right)^{-1}$. Note that $h$ is strictly increasing and weakly convex since $c^{\prime \prime}>0$ and $c^{\prime \prime \prime} \leq 0$. Let $z=g\left(\Delta_{3}-a\right)(1+\alpha) \Delta w-g\left(\Delta_{3}-a\right)(1+\beta) \Delta w$. Then

$$
\begin{gathered}
\Delta_{1}>h\left(g\left(a+\Delta_{1}\right)(1+\beta) \Delta w+z\right)-h\left(g\left(a+\Delta_{1}\right)(1+\beta) \Delta w\right) \\
\geq h\left(g\left(\Delta_{3}-a\right)(1+\beta) \Delta w+z\right)-h\left(g\left(\Delta_{3}-a\right)(1+\beta) \Delta w\right) \\
=h\left(g\left(\Delta_{3}-a\right)(1+\alpha) \Delta w\right)-h\left(g\left(\Delta_{3}-a\right)(1+\beta) \Delta w\right)=\Delta_{3}
\end{gathered}
$$


where the first inequality follows from the fact that $h$ is strictly increasing and $g\left(a+\Delta_{1}\right)(1+\alpha) \Delta w>g(a+$ $\left.\Delta_{1}\right)(1+\beta) \Delta w+z$ (since by assumption $\left.g\left(\Delta_{3}-a\right)<g\left(a+\Delta_{1}\right)\right)$ and the second from the convexity of $h$. But then $\Delta_{3}-a<$ $a+\Delta_{1}$ - a contradiction. Thus it must be that $e_{A, N A}^{L, H}>e_{A, N A}^{H, L}$. A similar argument shows that $e_{N A, A}^{H, L}>e_{N A, A}^{L, H}$. We conclude that $e_{A, N A}^{H, L}+e_{N A, A}^{L, H}-e_{N A, A}^{H, L}-e_{A, N A}^{L, H}<0$. The difference in average efforts exerted between the case where $p=1$ and the case where $p=0$ is therefore negative.

Proof of Proposition 9. The payoff from sorting workers into two segregated tournaments is

$$
\begin{aligned}
\Pi^{S}= & 2 p^{2} e_{A, A}^{H, H}+2 p(1-p)\left(e_{A, A}^{H, L}+e_{A, A}^{L, H}\right)+2(1-p)^{2} e_{A, A}^{L, L}+2 p^{2} e_{N A, N A}^{L, L}+2 p(1-p)\left(e_{N A, N A}^{H, L}+e_{N A, N A}^{L, H}\right)+2(1-p)^{2} e_{N A, N A}^{H, H} \\
& +T\left[p^{2}+(1-p)^{2}+4 p(1-p) G(a)\right]
\end{aligned}
$$

where the terms in the first and second line are the effort levels chosen in the tournament of the two ambitious workers and the two unambitious workers and the third line captures the benefits from promoting an able worker. Similarly, the payoff from sorting workers into two mixed tournament is

$$
\begin{aligned}
\Pi^{M}= & 2 p^{2}\left(e_{A, N A}^{H, L}+e_{N A, A}^{L, H}\right)+2 p(1-p)\left(e_{A, N A}^{H, H}+e_{N A, A}^{H, H}\right)+2 p(1-p)\left(e_{A, N A}^{L, L}+e_{N A, A}^{L, L}\right)+2(1-p)^{2}\left(e_{A, N A}^{L, H}+e_{N A, A}^{H, L}\right) \\
& +T\left[2 p^{2} q+2(1-p)^{2} r+2 p(1-p)\right]
\end{aligned}
$$

where $q=G\left(a+e_{A, N A}^{H, L}-e_{N A, A}^{L, H}\right)$ and $r=G\left(a+e_{N A, A}^{H, L}-e_{A, N A}^{L, H}\right)$ and $q \geq G(a) \geq r$. Note that, for simplicity, $V$ is normalized to 1 in both cases.

We can rewrite the profits from two segregated tournaments as

$$
\begin{aligned}
\Pi^{S}= & 2 p^{2}\left(e_{A, A}^{H, H}+e_{N A, N A}^{L, L}\right)+2 p(1-p)\left(e_{A, A}^{H, L}+e_{A, A}^{L, H}\right)+2 p(1-p)\left(e_{N A, N A}^{H, L}+e_{N A, N A}^{L, H}\right)+2(1-p)^{2}\left(e_{A, A}^{L, L}+e_{N A, N A}^{H, H}\right) \\
& +T\left[p^{2}+(1-p)^{2}+4 p(1-p) G(a)\right]
\end{aligned}
$$

and two mixed tournament as

$$
\begin{aligned}
\Pi^{M}= & 2 p^{2}\left(e_{A, N A}^{H, L}+e_{N A, A}^{L, H}\right)+2 p(1-p)\left(e_{A, N A}^{H, H}+e_{N A, A}^{H, H}\right)+2 p(1-p)\left(e_{A, N A}^{L, L}+e_{N A, A}^{L, L}\right)+2(1-p)^{2}\left(e_{A, N A}^{L, H}+e_{N A, A}^{H, L}\right) \\
& +T\left[2 p^{2} q+2(1-p)^{2} r+2 p(1-p)\right]
\end{aligned}
$$

We first show that average effort is always higher in segregated tournaments than in mixed tournaments. The difference in average efforts between segregated and mixed tournaments is strictly increasing in $\alpha-\beta$. For $\alpha-\beta=0$ the difference in average efforts is given by

$$
2[1-4 p(1-p)][g(0)-g(a)](2+\alpha+\beta) \geq 0
$$

since $1-4 p(1-p) \geq 0$ and $g(0)>g(a)$ and hence average effort is always higher in segregated tournaments. Segregated and mixed tournaments yield the same average effort if $\alpha-\beta=0$ and $p=1 / 2$.

Next, the difference in promotion benefits between segregated and mixed tournaments is given by

$$
T\left\{[1-4 p(1-p)](1-2 G(a))+2 p^{2}(G(a)-q)+2(1-p)^{2}(G(a)-r)\right\}
$$

where since $1-4 p(1-p) \geq 0,(1-2 G(a)) \leq 0$ and $q \geq G(a) \geq r$ the first two terms are negative and the third term is positive. Thus, depending on parameter values, this expression can be positive or negative. For $p=1 / 2$, segregated tournaments are better in terms of selection if $2 G(a)>r+q$. This proves Part (i).

Part (ii). Ambition and ability are perfectly negatively correlated $(p=0)$. The payoff that accrues to the firm when two segregated tournaments are simultaneously run is $2\left(e_{A, A}^{L, L}+e_{N A, N A}^{H, H}\right)+T$ since exactly one talented worker is promoted. The payoff when two mixed tournaments are run is $2\left(e_{A, N A}^{L, H}+e_{N A, A}^{H, L}+r T\right)$. Since $e_{A, A}^{L, L}>e_{A, N A}^{L, H}$ and $e_{N A, N A}^{H, H}>e_{N A, A}^{H, L}$, average effort is greater in segregated tournaments. Thus, for the mixed tournament setup to perform better, it must be that $T(2 r-1)$ is positive and sufficiently large. This is the case if $r>1 / 2$ (that is, if $a$ is large relative to $\alpha-\beta$ ) and $A$ is sufficiently large. This proves Part (ii).

Part (iii). Ambition and ability are perfectly positively correlated $(p=1)$. In segregated tournaments the payoff is $2\left(e_{A, A}^{H, H}+\right.$ $\left.e_{N A, N A}^{L, L}\right)+T$ since exactly one talented worker is promoted. In mixed tournaments, the payoff is $2\left(e_{A, N A}^{H, L}+e_{N A, A}^{L, H}+q T\right)$. Since $e_{A, A}^{H, H}>e_{A, N A}^{H, L}$ and $e_{N A, N A}^{L, L}>e_{N A, A}^{L, H}$ average effort is higher in the segregated tournaments, but the expected benefits from promoting a talented worker are higher when organizing mixed tournaments since $q>1 / 2$. This proves Part (iii).

\section{References}

Auriol, E., Renault, R., 2008. Status and incentives. RAND Journal of Economics 39, 305-326.

Baker, G., Gibbs, M., Holmstrom, B., 1994a. The internal economics of the firm: evidence from personnel data. Quarterly Journal of Economics 109, 881-920. Baker, G., Gibbs, M., Holmstrom, B., 1994b. The wage policy of a firm. Quarterly Journal of Economics 109, 921-956. 
Baker, G.P., Jensen, M.C., Murphy, K.J., 1988. Compensation and incentives: practice vs. theory. Journal of Finance 43, 593-616.

Baron, J.N., Bielby, W.T., 1986. The proliferation of job titles in organizations. Administrative Science Quarterly 31, 561-586.

Bartling, B., von Siemens, F., in press. The intensity of incentives in firms and markets: moral hazard with envious agents. Labour Economics.

Blau, F., DeVaro, J., 2007. New evidence on gender differences in promotion rates: an empirical analysis of a sample of new hires. Industrial Relations 46 , $511-550$.

Bolton, G.E., Ockenfels, A., 2000. ERC: a theory of equity, reciprocity and competition. American Economic Review 90, $166-193$.

Clark, A.E., 1997. Job satisfaction and gender: why are women so happy at work? Labour Economics 4, 341-372.

Clark, A.E., Frijters, P., Shields, M., 2008. Relative income, happiness, and utility: an explanation for the Easterlin paradox and other puzzles. Journal of Economic Literature 46, 95-144.

Clark, A., Oswald, A., 1996. Satisfaction and comparison income. Journal of Public Economics 61, 359-381.

Demougin, D., Fluet, C., 2003. Inequity Aversion in Tournaments. Cahiers de recherche 0322, CIRPEE.

DeVaro, J., 2006. Internal promotion competitions in firms. RAND Journal of Economics 37, 521-542.

Doeringer, P., Piore, M.J., 1971. Internal Labor Markets and Manpower Analysis. Heath and Company, Lexington, MA.

Dur, R., Glaser, A., 2008. Optimal contracts when a worker envies his boss. Journal of Law, Economics, and Organization $24,120-137$.

Englmaier, F., Wambach, A., 2005. Optimal Incentive Contracts Under Inequity Aversion. IZA Discussion Papers 1643, Institute for the Study of Labor (IZA).

Falk, A., Knell, M., 2004. Choosing the Joneses: endogenous goals and reference standards. Scandinavian Journal of Economics 106, 417-435.

Fehr, E., Schmidt, K., 1999. A theory of fairness, competition, and cooperation. Quarterly Journal of Economics 114, 817-868.

Fehr, E., Schmidt, K., 2003. Theories of fairness and reciprocity - evidence and economic applications. In: Dewatripont, M., Hansen, L.P., Turnovsky, S.J.

(Eds.), Advances in Economics and Econometrics, Eighth World Congress of the Econometric Society, vol. 1. Cambridge University Press, Cambridge, pp. 208-257.

Fershtman, C., Hvide, H.K., Weiss, Y., 2003. A behavioral explanation of the relative performance evaluation puzzle. Annales d'Economie et Statistique 71-72, 349-361.

Fershtman, C., Hvide, H.K., Weiss, Y., 2006. Cultural diversity, status concerns and the organization of work. Research in Labour Economics 24, 361-396.

Frank, R.H., 1984. Interdependent preferences and the competitive wage structure. RAND Journal of Economics 15, 510-520.

Frank, R.H., 1985. Choosing the Right Pond: Human Behavior and the Quest for Status. Oxford University Press, Oxford.

Gill, D., Stone, R., 2009. Fairness and Desert in Tournaments. Working Paper. University of Southampton.

Gneezy, U., Niederle, M., Rustichini, A., 2003. Performance in competitive environments: gender differences. Quarterly Journal of Economics 118, $1049-1074$.

Goel, A.M., Thakor, A.V., 2006. Optimal Contracts When Agents Envy Each Other. Working paper. Washington University in St. Louis.

Grund, C., Sliwka, D., 2005. Envy and compassion in tournaments. Journal of Economics and Management Strategy 14, $187-207$.

Harbring, C., Irlenbusch, B., 2003. An experimental study on tournament design. Labour Economics 10, $443-464$.

Harbring, C., Irlenbusch, B., 2008. How many winners are good to have? On tournaments with sabotage. Journal of Economic Behavior and Organization $65,682-702$

Heath, C., Larrick, R., Wu, G., 1999. Goals as reference points. Cognitive Psychology 38, 79-109.

Hewitt, P., 2003. More Female Directors Make Board Level. http://www.number10.gov.uk/Page4804 (accessed 15.03.10).

Huberman, B.A., Loch, C.H., ler, A., 2004. Status as a valued resource. Social Psychology Quarterly 67, $103-114$.

Itoh, H., 2004. Moral hazard and other-regarding preferences. Japanese Economic Review 55, 18-45.

Kahneman, D., Tversky, A., 1979. Prospect theory: an analysis of decision under risk. Econometrica 47, $263-292$.

Kahneman, D., Tversky, A., 1992. Advances in prospect theory: cumulative representation of uncertainty. Journal of Risk and Uncertainty, 297-323.

Koszegi, B., Rabin, M., 2004. A model of reference-dependent preferences. Quarterly Journal of Economics 121, 1133-1165.

Lazear, E.P., 1989. Pay equality and industrial politics. Journal of Political Economy 97, 561-580.

Lazear, E.P., Rosen, S., 1981. Rank-order tournaments as optimum labor contracts. Journal of Political Economy 89, 841-864.

Nalebuff, B.J., Stiglitz, J.E., 1983. Prizes and incentives: towards a general theory of compensation and competition. Bell Journal of Economics $14,21-43$.

Ransom, M., Oaxaca, R.L., 2005. Intrafirm mobility and sex differences in pay. Industrial and Labor Relations Review 58, $219-237$.

Rey Biel, P., 2008. Inequity aversion and team incentives. Scandinavian Journal of Economics 108, 297-320.

Robson, A.J., 1992. Status, the distribution of wealth, private and social attitudes to risk. Econometrica 60, 837-857.

Teulings, C., Hartog, J., 1998. Corporatism or Competition? Labour Contracts, Institutions and Wage Structures in International Comparison. Cambridge University Press, Cambridge.

Zizzo, D.J., 2002. Between utility and cognition: the neurobiology of relative position. Journal of Economic Behavior and Organization 48, 71-91. 